\title{
Verbal expressions of aggressiveness on the Estonian Internet ${ }^{1}$
}

\author{
Liisi Laineste
}

\begin{abstract}
The focus of this paper is on the nature and role of online aggression in larger scale societal tensions and its interaction with the use of humor. The study analyses expressions of online aggression in different online environments. The study involves content analysis of online media from discussion forums and less regulated social media like blogs. The material was gathered for a research coordinated by the Ministry of Justice in Estonia, and it covers the time span of eight years: 2000-2007. The discussion addresses three types of sources in particular (1) anonymous comments (2) thematic forums and social networking media, and (3) blogs. This allows for insights into how anonymity affects the contents of electronic utterances, including the degree of aggression in them. We aim to describe the phenomenon of online aggressiveness in general: its extent, content, and context. Attention is given to how verbal aggression on the Internet goes hand in hand with banter, or friendly teasing. An overview of the flaming/ joking patterns in the commentaries leads to the questions on how humour is embedded in Internet flaming, and finally to the dynamics of "us" and "them" in the material. In this way, the paper touches upon the very narrow and hard-todefine line between aggression and humour.
\end{abstract}

Keywords: Internet, online aggression, humour

\section{Introduction}

Aggression is an ever-present part of human society, although its expression differs across societies and cultures. In face to face interaction, its appearance is socially inhibited, and means of mass communication have been censored for their aggressive content, but the development of computer mediated communication (CMC) has shaped the interaction that occurs within the Internet, pushing it to be more liberal and disinhibited. This growing permissiveness enhances new features of Internet communication: it allows for more interactivity and provides more detailed information compared to print media, radio

\footnotetext{
1 The research was supported by ETF8149.
} 
and TV (Tsfati \& Weimann 2002) although the information it provides may be more shallow, dispersed and biased, depending on the source. However, while earlier communication technologies may have had their share in shaping the message, they did not offer the same capacity for invoking as many fundamental social psychological processes that can be related to aggressiveness as does the Internet (Malamuth et al. 2009: 166). The change in content is related to the size, cultural background and interactivity with the audience as well. People have always been emotional about their environment and have wanted to discuss it with others - above all with those who think like them. In a closed social group, e.g. in a rural setting a few hundred years ago, the discussions were held within this group, and the reactions (likes and dislikes) of the others could be predicted, but nowadays these predictions are no longer valid. In both closed (participants must be logged in) and open (accessible to anyone) online environments, the members do not know each other that well and cannot foresee what the audience's reaction will be. Aggressive acts of communication on the Internet - ridiculing, naming, swearing, banter, or in general, flaming - reach a huge anonymous audience, whose reactions vary from one end of the scale to another; from support to definite rejection. The reactions to aggression may be unexpected to the initiator (if the insult was unintentional or, perhaps, meant as a joke) and can even result in actual physical violence (e.g. the Danish cartoon controversy in 2006, which exploded some months after a set of editorial cartoons about Muslims were published in a Danish newspaper Jyllands-Posten; in subsequent reactions, protestors burned flags, organised consumer boycotts, attacked Danish embassies, etc.).

Verbal aggression online can be termed generally as flaming. Flaming as a notion was already coined during the early years of the Internet. It initially referred to incessant talking or pointless chatter (for the history of the term, see Joinson 2007: 79). Since then, it has included everything from impoliteness and swearing to excessive use of exclamations and superlatives (Kiesler et al. 1985). It has come to be seen as a common term to designate any negative and antisocial verbal behaviour on computer networks - e.g. as a "form of personal verbal violence arising largely from the peculiar conditions of online writing" (Millard 1997: 145; see also a number of definitions cited by Tereszkiewicz 2012). Points that most researchers agree upon are that flaming is uninhibited, heated and emotional venting that occurs on computer networks. Anonymity and volatile identities are factors which contribute to engaging in online flaming, but globalisation also plays its part.

Flaming is not the only way to express aggression online. It can use the form of online communication in chat rooms and forums, but it can be also expressed through racist websites, stealing virtual identities, stalking, creat- 
ing and spreading computer viruses, and much more. In most cases though, aggression is expressed through words, because above all, the Internet is a medium for written speech. The rise of other media (especially video) that spread across the Internet cannot be underestimated, but written expression has still remained more important - and is more often hostile. In real life, people have an almost limitless array of behaviours besides words - they can use verbal or physical assault, or just give an angry look, and their body language will, under normal conditions, support their message. The online environment gives a much more limited set of options for expressing oneself. This has been described by a number of studies into CMC (e.g. Hine 2005: 7) where the Internet has been referred to as an impoverished medium. As already mentioned above, there are also non-verbal means of aggressive behaviour online. These include cyberbullying and ignoring a person (frequently found among teens (Livingstone et al. 2011: 61-70), also reported among Estonian schoolchildren (Rudi 2011), or maintaining hate-promoting websites (not so common in Estonia, but see Oring 2003 and Wallace 1999: 130-132 for studies about USA). In this study, I will concentrate on the most visible and easily recordable one, verbal aggression, referring to it as flaming.

A growing body of research in the field of Internet studies investigates the factors that enable the growing presence of aggressive statements online. So far, the main factor blamed for causing online aggression is the anonymity of the medium, but this is far from being the only one, as more recent studies show. Malamuth et al. (2009: 168) gives an overview of reasons for online aggression, showing that there are a number of interactive factors that influence it. Instead of approaching the material from a single theory (for a concise cross-section of these, see Tereszkiewicz 2012), they break the existing evidence down to three separate categories. The three main incentives for flaming are (1) those creating the motivation for aggression, (2) those reducing internal and external inhibitions that might prevent acting out the desire to aggress, and (3) those providing the opportunity for the act to occur (Malamuth et al. 2009: 168). First, motivation to aggress is reinforced by the uncensored omnipresence of the Internet, which is more interactive, expecting the audience to get involved. Online video games, for example, sometimes allow using scanned images of the player as characters in the game, and violent actions get rewarded by visual / sound effects and advancement in levels. Therefore, when sitting behind the computer, people are conditioned to aggress via classical and instrumental conditioning and an observational learning process (Chambers \& Ascione 1987). Secondly, disinhibition is also affected by a number of factors: primarily, anonymity, but also the lack of direct censorship, because the Internet is decentralised and being alone at the computer reduces social mores and embarrassment, and social 
support for even the most aggressive content reinforces the hostile choices of the Internet user. Last but not least, opportunities for aggression are created by the ready availability of targets in social networks and chat rooms, where excessive self-disclosure may lead to dramatic results. Besides, their depersonalised nature, or the fact that they may live thousands of miles away from the aggressor, only makes it easier for the aggressor to justify the hostile actions. In addition, correlation studies from psychology have shown that the tendency to flame can be backed up by some personality traits, e.g. high levels of assertiveness and sensation seeking (Alonso \& Aiken 2002). Also, males tend to engage in flaming more than females (Aiken \& Waller 2000). Relying on this, we can conclude that there are a number of mutually supportive reasons for online aggression. At the same time, some features of the Internet might actually foster sociability and agreeableness instead of aggression. Joinson (2007) stresses that it is essential not to reduce the reasons for heightened aggression only to a single factor - anonymity. The contexts of engaging in online environments differ and so does the level of disinhibition that triggers flaming. The present study will look at different contexts while keeping this perspective in mind, trying to differentiate between the specific characteristics of various contexts and their interrelation with flaming that occurs in this context.

Although the scope of Estonian-language Internet is in no way comparable to the almost limitless English-language Internet, I have chosen the latter as the target of my present research. The study sets out to define the characteristics of flaming in Estonian. Precisely because of its graspable size, this material is much more useful in describing the full phenomena and above all its dependence on the level on de-individuation (term coined in 1952 by Leon Festinger et al.) of the specific contexts. The levels are prone to vary according to how anonymous the users can remain to their audience and what are the group norms in the particular environment, ranging from commentary boards and forums to social media and blogs.

First, I will present the data from a research of online media in 2007, aiming to map xenophobia on the Estonian Internet, i.e. describing the use of verbal aggression directed against some more common groups in Estonia (see also Laineste 2007). This part of the study thus describes the main objects of online flaming and the social and contextual background of the target choice. I will then proceed to describe three different sources in the dataset (above of all, anonymous comments, but also social media / forums and blogs), and point out some essential differences. And, finally, I will give a few examples of verbal aggression that come hand in hand with humour, blurring the boundaries between flaming and joking. 


\section{Material and method}

The data of this research covers the years 2000-2007, ranging from comments drawn from the most popular news portal www.delfi.ee to data gathered from two forums, two popular social networking media, and three blogs from the same time span. The largest body of material was drawn from commentaries in the Delfi news portal. From each year, a random week was chosen (from different months in order to avoid recurring subjects that might surface due to yearly national holidays or seasonally hot topics). The two most popular (most frequently commented) news texts of this week together with their comments were included in the database. This resulted in 22,625 comments from 126 news texts over the eight years. The topics of the news items ranged from local politics to miscellaneous facts, but a common factor was that all of these dealt with a clearly defined "other", be it (Black, Russian) immigrants, homosexuals, politicians or other social / ethnic groups, which seemed to be the motivation for a heightened interest in taking part in the discussion. In the analysis below, the frequency of different "others" will be presented. The extremely disinhibited, open and unregulated context of the online news portal was then compared to other online contexts with more established social norms and less freedom. In order to analyse how the context and setup of a problem affects the use of aggressive language use, I selected two forums that dealt with specific issues (nationalism and religion), observed online communication of social network users with racist interests (fighting against immigrants, homosexuals, etc.), and selected blog entries dealing with similar subjects. The two forums acted as a popular hang-out for similarly-minded people, one gathering Internet users with nationalist interests (Eesti Rahvuslik Liikumine ('Estonian nationalist movement'); www.rahvuslikliikumine.ee/foorum/) and the other Christian Estonians (Eesti Kristlik Foorum ('Estonian Christian Forum'); foorum.usk.ee/), ending up with 2,000 texts (comments in forums from most popular threads throughout 2000-2007). The material from social networks originates from two portals: Rate (www.rate.ee) where teenagers can rate each other's pictures but also create their profile by stating their interests and participating in corresponding chat rooms, etc.; and from that time period the favourite social networking media for Estonians Orkut (www.orkut.com, preceding Facebook) where people indicated their favourite topics by participating in interest groups (resulting in 330 comments from group discussions). Blog entries (3) were chosen from the same time period, using a blog search engine blogtree.ee, with search words that predicted some kind of emotional blog entry ("racism", "nigger", "gay" and similar). Table 1 presents the material in a concise manner: 


\begin{tabular}{|l|r|}
\hline Type of the source & Number of texts \\
\hline Public comment board, anonymous & 22,625 \\
\hline $\begin{array}{l}\text { Social networking (rate.ee, orkut.com); forums (Esto- } \\
\text { nian Christian Forum, Estonian Nationalist Forum) }\end{array}$ & 2,330 \\
\hline Blogs & 3 \\
\hline
\end{tabular}

Table 1. Types of source material included in the study.

In terms of their characteristics of online context, these sources vary from very open and permissive to carefully controlled and self-reflexive. This scale was expected to be visible in the results, while answering the following research questions:

- Is there a difference in the frequency of flaming across these contexts?

- Who are the groups most often targeted in flaming?

- How does the frequency of flaming relate to the provocativeness of the stimulus (news text, opening post in forum or social network discussion group, and incentive for a blog post) and other features that are available for analysis in the specific online context (e.g. interests and education levels of the participants, etc.)?

- How does aggressive content interact with the attempted use of humour?

To characterise the targeted contexts in a few words, Delfi is an environment that is closest to providing an arena for anonymous free speech. After some polemics and one person convicted for hate speech in 2005, a button to report abuse was created, but the portal still remains a paradise for flamers. It is an ever-popular news portal that was designed to collect the highest number of clicks from the readers, and the commentators are aware of the permissiveness this implies. The Nationalist and Christian forums are open for reading, but only a member can post there. There is not much content of interest for the "non-believer" (be it believing in God or eugenics), which makes the members post according to the group norms and without considering the wider audience. The norms prescribe to stand for some principles and strongly advocate against others (anti-homosexualism in the Christian forum, for example). Social norms are very visible in the content of the forums, and as forum members usually know each other (many also in real life, through common social events), anonymity is fairly low. Rate and Orkut are also low in anonymity, because people sign in 
with a relatively personalised and recognisable profile. The reasons for this vary: Orkut was a place to connect with friends or (to a lesser extent) find new ones, thus in order to add them to your network, one had to be "visible", i.e. present a real picture / profile details; Rate was often used as a dating portal, which also means real pictures / profile details had to be posted. The pictures in the latter had to be, in fact, approved by the moderator in order to finally appear on the site, and it was difficult, if not impossible, to post fake pictures. Profile details and comments in discussion groups were not moderated, but nevertheless reflected the real interests of the portal members and thus had to be socially acceptable to the majority. Both Orkut and Rate gathered together masses of people (worldwide, Orkut still has 66 million users and Rate, an Estonian site, has a total of 303,282 users) all with their own preferences, which results in less specific social norms than forums, but equally low anonymity. The last category, blogs, presents quite a different genre from the others mentioned above, because these are usually designed to meditate upon some phenomena in a reflexive manner, which normally rules out straightforward aggressiveness. Besides, popular bloggers are usually not afraid of presenting themselves to their audience, even if they do use a pseudonym for posting entries; furthermore, they are aware and proud of their position as a public persona or an opinion leader. This makes the context relatively low in aggressiveness as well as anonymity, whereas its social norms are adapted to the imaginary audience.

The material was analysed by content analysis, using the qualitative data analysis tool QDA Miner. Low, medium and strong levels of aggression divided into a number of subcategories were tagged in the database (following Verkhovsky 2006), and general statistics graphs were created on the basis of this. The programme also enables to analyse the interaction between two or more categories (in this case, we analysed the interaction between different levels of aggressiveness and humour).

\section{Results and discussion}

Similar to the categories suggested by Verkhovsky (2006), adjusted to the Estonian material through categorising a pilot sample, online aggression was categorised into three levels: mild, medium and strong aggression. I will give an overview of each subcategory, furnishing the descriptions with examples where needed. Strong aggression was tagged when a text expressed straightforward violence: displayed nationalist or racist slogans, called for physical actions against "others", and praised historical violence (in this case, against Gypsies; Delfi): 


\section{Liisi Laineste}

Oh jumal küll ... Elagu Hitler kes hävitas paska! (jõhvikas 5.10.2006)

Oh my god ... Long live Hitler, who eradicated such shit!

Those comments that use the conditional were also categorised as being strongly aggressive, e.g. (Delfi):

tallinnas peaks ka peksma hakkama neid pakse värdjaid somme ja filmima :D (Väänik 12.01.2007)

We should also start beating and filming those fat Finnish bastards :D

Medium aggression was divided into the following subsections: using or introducing new negative stereotypes about the "other", swearing, accusing of stupidity, naming and slurs (Delfi):

98\% kurjategijatest on venelased! (to vene neiu 19.08.2005)

$98 \%$ of all criminals are Russians!

Rohkem kui pedenduse all kannatavad tüübid tähelepanu puuduse all. (Jyri 15.08.2005)

These guys suffer from a lack of attention even more than faggotry.

luterlased on ühed igavese nokkud! (Tainas 7.05.2003)

Lutherans are infinite dicks!

Finally, mild aggression occurred when jokes and other forms of humour were used (excluding some sharp forms of irony which was tagged under medium aggression), the target was presented in a negative context, claimed to possess negative influence, others were sharply accused of flaming, racist viewpoints were referred to or a previous flame was cited without any counter-arguments (Delfi):

mis on 500 pedet põllul? - väetis (V 15.08.2005)

What do you call 500 fags on a field? - Manure

see euroliit on sama põhimõttega mis endine nsvliit, ega erilist vahet ei näe ma kyll sellel. (megamees 3.02.2001)

European Union follows largely the same principles as the former Soviet Union, so I don't see much of a difference there.

The overall average percentage of strong verbal abuse on the Internet amounted to $2.9 \%$. All in all $11.3 \%$ of all comments can be tagged for mild to severe flaming. Although we will not give a detailed report of changes across the eight years 
within the limits of this paper, it is interesting to point out that the levels and their proportions did not change much, and the total share of flaming comments in the Estonian-language CMC has largely remained the same. Small changes did occur in Delfi after 2002 and 2003 when the level of medium aggression first passed the level of mildly aggressive comments, and after some further case analysis this was attributed to the fact that news texts became increasingly more provocative in 2002. Thus, a slight but constant rise in the medium level of flaming was recorded in the material, whereas the other two levels remained more or less the same. We can say that the majority of comments and statements in CMC are neutral, and an average of one in ten texts can be tagged for flaming. The results suggest that a moderate share of aggression is inherent to the medium, especially in the form of mild aggression (5\%; followed by medium and strong aggression, $3.4 \%$ and $2.9 \%$ respectively). For an overview of the results, see Table 2 :

\begin{tabular}{|l|l|l|l|l|}
\hline & $\begin{array}{l}\text { Delfi } \\
\text { comments }\end{array}$ & $\begin{array}{l}\text { Forums / } \\
\text { social media }\end{array}$ & Blogs & Average \\
\hline Mild & 2.2 & 11.4 & 1.3 & $\mathbf{5}$ \\
\hline Medium & 7.5 & 2.7 & 0 & $\mathbf{3 . 4}$ \\
\hline Strong & 7.2 & 1.5 & 0 & $\mathbf{2 . 9}$ \\
\hline $\begin{array}{l}\text { Total share } \\
\text { of flaming }\end{array}$ & $\mathbf{1 6 . 9}$ & $\mathbf{1 5 . 6}$ & $\mathbf{1 . 3}$ & \\
\hline
\end{tabular}

Table 2. Share of aggressive statements in the material (of all comments / forum entries), \% of words in entire blog entry.

This allows us to answer the first research question: different online contexts do differ in the levels of aggression, with the highest occurrence of flaming in Delfi news comments (16.9\%), and the lowest in blogs (1.3\%). Forums and social media are more similar to commentary boards than blogs, but at a closer look we notice a fine difference in the levels of aggression: mild aggression is prevalent in forums and social media, whereas examples of strong flaming can hardly be found there, which in fact draws them closer to blogs than to commentary boards. Besides, the instances of flaming on the whole occur there more rarely and only in the framework of a few heated discussions where things can get out of hand.

These findings can be discussed in the light of the theoretical framework presented above, namely that online aggression is the result of a formula that 
includes motivation, inhibition and opportunities provided by specific online contexts, and not only a by-product of the anonymous environment as a whole. News portals do not usually require users to $\log$ in, even for commenting. This is an outcome of their ambition to inflate the number of visitors - and people are attracted to visit the site, read the news, and, more importantly, the comments, where they can expect a good shot of adrenalin. Not all visitors comment, but they implicitly favour the action, the "blood and tears" that the commentators provide. This motivates the commentators to outplay each other in their wittiness, cleverness, and aggressiveness in order to make themselves visible to and be appreciated by the audience. It is the silent majority that also regulates inhibition through choosing not to report unsuitable, e.g. xenophobic comments, even if the option exists. And, most importantly, there are plenty of opportunities for aggression provided by the journalists: the titles of news items as well as the presented points of view are often formulated in a way that provokes aggressive reactions, or even better, a clash of opinions. In forums and social media, social norms do not support straightforward and strong flaming. This is seen in prompt reactions to inappropriate speech, where other members refer to a removed post or warn the aggressor about removing one if he/she does not take the words back or argument the point of view. In social media, where racist or other aggressive discussions remain inside a group of friends who probably know each other well, in-group inhibitions are smaller, but as flaming lacks the aspect of motivation - everybody has signed in the group or marked it among his/her interests - aggressive statements do not prevail. In terms of opportunities, the thread starters may at times be fishing for flaming ("Special-fuck-off-to-baranka-people" (a name of a rate.ee interest group, referring to Russians); Pedeparaad ('Fag parade'), Estonian Christian Forum 6.10.2005), but more often the topics are formulated neutrally. Blogs provide no motivation for flaming because the expectation of the readers is to read about personal attitudes rather than witness non-argumented venting, except for a few flame-dedicated blogs which also exist. There, flaming is used as a tool to give the blog a character and readers take it as humour, but in most blogs authors are motivated to keep their face and inhibit their aggression. The availability of opportunities is also controlled by the authors themselves - they decide upon the degree of anonymity and also choose the topics, be it in the form of a daily diary, political commentary or something else.

News comments are the most obvious place to look for online aggression. We can find examples of strong flaming (delfi.ee):

MG3 lühemas lindis on 50 pauku, palju ühe tõpra peale, mina paneks neid 5 tükki üheteise taha ritta seisma ja laseks ühe pauguga kõik läbi. Oleme kokkuhoidlikud, ei maksa sita pärast laristada. (Juss 19.03.2002) 
MG3 short belt has 50 shots, too many for one bastard, I would put 5 of them behind one another and shoot them with one shot. Let's be parsimonious, no need to spend on this shit.

Blogs, on the other hand, may present a few cases of depicting the "other" in a negative context, but never resort to strong or medium aggression (humalake. blogspot.com):

Vähemalt ühendab mind kui eestlast tema kui venelasega ühine eelarvamus türklaste vastu!

At least what connects me as an Estonian to her as a Russian is our shared prejudice about Turks!

The forums and social media remain between these two extremes, but mostly display mild forms of aggression. Medium and strong levels also exist, but to a lesser extent (for an example of medium aggression, negative stereotyping is used; orkut.com):

Nii omane on ju venelastele, et rünnatakse karjaga .. fuckinäpu näitamine, ropendamine, karjumine, räuskamine, rü̈̈stamine. (user: Marju 3.05.2007)

So typical of Russians: they attack as a mob .. show the middle finger, swear, yell, brawl, loot.

But also some very strong hostility was present, even more than can be encountered in news comments (rate.ee):

I HATE NIGGAS, JEWS, MUSLIMS AND HOMOSEXUALS!!! (ESTunit, user: hormon)

Although this kind of exclamations are marginal, they meet a more permissive context in social media (though maybe not in Facebook or Orkut where social awareness and control is higher) because they channel people with similar interests into groups, which motivates them to express particular (even exaggerated) viewpoints in order to feel a part of the group. A different kind of flaming can be met in forums, where a few more active members (opinion leaders) remind the other forum users what a true Christian or nationalist must believe in (Estonian Christian Forum):

Islam on INIMKONNA SAATANLIK KATK! Jeesus Kristus tulles planeedile tagasi JUURIB VÄLJA selle saatanakummardamise - poolkuu jumalama kummardamise! [...] (R. Crusoe 31.12.2006)

Islam is a satanic pest for mankind! Jesus Christ will eradicate this cult of Satan - worship of the crescent god - when he returns! 
The most common targets are different national groups: the Russians dominate (average of $11 \%$ of all groups), but also Jews, Americans, Blacks and Asians occur; other more popular groups include religious groupings and homosexuals. Arguments and flaming rarely become personal, more often they are targeted against the group triggered by the article (especially if the article is formulated in a provocative way); but if representatives of the targeted group claim to be present in the online discussion, the debate becomes even more heated and personal insults are frequent. In terms of the levels of flaming, it is interesting to note that Russians are the only "other" against whom strong levels of aggression emerge. In other cases, strong and straightforward aggression is used against groups who can be seen as accidental targets (Finns, Christians, homosexuals) - not often flamed, but if a specific news text provokes the commentators, they use their full arsenal. And in general, the "others" are all blamed for similar things, even if the targets differ considerably: having negative influence on life quality, fostering crime, being cultureless, etc.

Provocation is most often the reason for a heightened inclination to use xenophobic or similarly aggressive statements. In blogs, the stimulus for writing a post usually comes from real life encounters, but also the media. In other online contexts that we have examined here, the news text or a thread starter is the stimulus. It is worth looking at the comments and posts that follow a provoking news text/ thread starter or a neutral one. Here we see a clear tendency for more aggressive comments to appear in the case of provokingly verbalised news or posts (e.g. the case of a local priest who beat a stray dog in Koerapeksja pääses väga väikese karistusega ('Dog beater got away with a very small fine'), Delfi:

Ainult tillipidi rauda ja veel peksta puuhaluga mööda perset seda kogudusevanemat (oh 7.05.2003)

Jam his dick in a caltrop and beat this priest's ass with a log

Even as much as $31.7 \%$ of comments and posts contained flaming when the title was provocative. At the same time, neutral texts received $3.01 \%$ of aggressive replies. While looking at the demographic data that comes from social media and forums, the tendency to use flaming online was higher when the Internet user was male, living in bigger cities (Tallinn, Tartu), had only secondary or vocational education, and was 17-19 years old. 


\section{Flaming and humour}

Humour was a subcategory of mild aggression in the material (see above, the beginning of discussion section). In some cases we can say that it is intuitively true: aggressive acts can seem funny (slapstick comedy is built on this implication), and, without the context, much of what can be called humour may sometimes offend people. This means that humour and aggression often go hand in hand (see also Gruner 1997). Funny nicknames for other nations or social groups / subcultures, for example, belong here. In all of the online contexts studied within the limitations of this study, flaming often did not actually stem from the genuinely hostile intentions of the Internet users; instead, they were interested in getting attention, sounding novel and representing the norms of the group they wanted to belong to. The authors of these statements might have had, no doubt, strong attitudes towards the issue in question, but they were also motivated by the responses to fellow commentators and the wish to be simply noticed within the thread. The message and its tone is usually a result of attitudes combined with motivation, disinhibition and an opportunity to aggress, all embedded in the situation. Researchers have discovered that the same flamers may "attack" different contexts with similar flames (Aiken \& Waller 2000). Exchanging witty remarks can often take the form of seemingly offensive statements, although it is in fact just rough-and-tumble play (only, of course, if both or all participants perceive it as such) (Kendall 2002). Some researchers have made a distinction between flaming and spamming, only the latter of which can be ludic and the former is always hostile (e.g. see Crystal 2001). This differentiation is, nevertheless, rather impossible to use in research because it is reduced to the intentions of a communicator - and these are not easily identifiable within CMC. The solution would be not to forcefully try to distinguish between humorous and aggressive posts / comments, but instead follow the parallel tendencies within the wider communicative context (the development of threads from aggressive to humorous or vice versa is above all affected by the reactions of fellow commentators, Laineste 2010). The main point here is that straightforward verbal aggression is actually too limited to express negative emotions and very often humour (or rather, irony) comes to the rescue here. Christie Davies (2002) has argued that there are many easier and quicker ways of expressing anger than through humour, but people quite often prefer the more difficult and slower way because simple aggression is boring and unexciting. They need to add spice: make it sound funny, witty, and playful. For example, commentators write about the most flamed group, Russians: "A communist is as familiar with culture as a pig with Sunday habits" (rate.ee; galil 04.02.2001), or play with sounds in finding new ways of calling the "other" 
in nicknames and ethnic slurs ("Yestonyans" = Russian immigrants living in Estonia, not being able to pronounce the name of their nation). Irony is another way to make a point through humour (e.g. "A lot of cute dark-skinned eurostandardised offspring to you, who are in favour of the European Union!" (Delfi; Juhuslik Suusataja, 29.01.2001)). Humour can be viewed as an alternative to verbal aggression at times when a direct verbal attack has worn out or wittiness is needed in the argument. This often happens in a string of comments after initial emotions have been poured out and successive playful banter follows.

\section{Conclusions}

The results show that aggression is not prevalent, but nevertheless it is a constant part of an online environment.

There are differences in the online contexts that we have described, with the highest proportion of aggression in commentary boards, followed by forums and social media, and the least in blogs. This can partly be explained by the degree of deindividuation and anonymity, but it does not explain the differences between social media and blogs, where the user can be identified with ease. Rather, the differences stem from social rules imposed by the context itself and the motivation, inhibitions, and opportunities it presents for flaming.

Internet commentators play with the concepts of normal and abnormal, right and wrong, good and bad, while naming the "other". They display their (sometimes radical) nationalism through juxtaposing themselves to "abnormal groups". The majority of offensive slang on the Estonian Internet is directed against Russians, but homosexualism and religion are also targets of dysphemisms. The use and density of flaming also depends on many contextual cues: the news story and its construction, its main subjects, the identity or attitudes of the commenting persons, social context of the news, etc. This leads us to assume that encouraging (xenophobic and other) emotions is in the very nature of CMC. Even when people step up against racism or flaming as such in their comments, this may be motivated by the wish to play the devil's advocate, adapt for a moment a new identity just for the sake and fun of the discussion. People are drawn to the emotional charge they get when they read a provoking text and a chance to react to that. 


\section{References}

Aiken, Milam \& Waller, Bennie 2000. Flaming among first-time group support system users. Information and Management, Vol. 37, No. 2, pp. 95-100.

Alonzo, Mei \& Aiken, Milam 2002. Flaming in electronic communication. Decision Support Systems, Vol. 36, No. 3, pp. 205-213.

Chambers, John H. \& Ascione, Frank R. 1987. The effects of prosocial and aggressive video games on children's donating and helping. Journal of Genetic Psychology: Research and Theory on Human Development, Vol. 148, No. 4, pp. 499-505.

Crystal, David 2001. Language and the Internet. Cambridge: Cambridge University Press.

Davies, Christie 2002. Mirth of nations. New Brunswick, N.J.: Transaction Publishers.

Festinger, Leon \& Pepitone, Albert \& Newcomb, Theodore M. 1952. Some consequences of de-individuation in a group. Journal of Abnormal and Social Psychology, Vol. 47, pp. 382-389.

Gruner, Charles R. 1997. The game of humor. New Brunswick: Transaction Publishers.

Hine, Christine 2005. Virtual methods: Issues in social research on the Internet. New York: Berg Publishers.

Joinson, Adam N. 2007. Disinhibition and the Internet. In: J. Gackenbach (ed.) Psychology and the Internet: Intrapersonal, interpersonal and transpersonal implications (2nd edition). San Diego, CA: Elsevier Academic Press, pp. 76-92.

Kendall, Lori 2002. Hanging out in the virtual pub: Masculinities and relationships online. Berkeley: University of California Press.

Kiesler, Sara \& Zubrov, David \& Moses, Anna M. \& Geller, Valerie 1985. Affect in computer-mediated communication: An experiment in synchronous terminal-to-terminal discussion. Human-Computer Interaction, No. 1, pp. 77-104.

Laineste, Liisi 2007. Rassism ja ksenofoobia Eesti Internetis (2000-2007): Internetikommentaarid, foorumid, suhtlusportaalid ja blogid. [Racism and xenophobia in Estonian Internet: Comments, forums, social networking media and blogs.] http://www.just.ee/ orb.aw/class=file/action=preview/id=54339/Rassism + ja + ksenofoobia_18.05.2011.pdf, last accessed on 21 May 2012.

Laineste, Liisi 2010. Äpardunud huumor internetikommentaarides. [Failed humour in Internet commentary boards.] Keel ja Kirjandus, Vol. 9, pp. 655-670.

Livingstone, Sonia \& Haddon, Leslie \& Görzig, Anke \& Òlafsson, Kjartan 2011. Risks and safety on the Internet. The perspective of European children. London: EuKidsOnline. (www.eukidsonline.net).

Malamuth, Neil \& Linz, Daniel \& Yao, Mike 2009. The Internet and aggression: motivation, disinhibitory and opportunity aspects. In: Y. Amichai-Hamburger (ed.) The social net: Human behavior in cyberspace. New York: Oxford University Press, pp. 163-191. 


\section{Liisi Laineste}

Millard, William B. 1997. I flamed Freud: A case study in teletextual incendiarism. In: D. Porter (ed.) Internet culture. New York: Routledge, pp. 145-159.

Oring, Elliott 2003. Engaging humor. Urbana/Chicago: University of Illinois Press.

Rudi, Hanneli 2011. Eesti juhib küberkiusajate edetabelit. [Estonia is ranking highest in cyberteasing.] Postimees, 5 October. http://www.postimees.ee/586664/eesti-juhibkuberkiusajate-edetabelit/, last accessed on 2 April 2012.

Tereszkiewicz, Anna 2012. Do Poles flame? Aggressiveness on Polish discussion groups and social networking sites. In: L. Laineste \& D. Brzozowska \& W. Chłopicki (eds.) Estonia and Poland. Creativity and tradition in cultural communication, Vol 1. Tartu: ELM Scholarly Press, pp. 221-236.

Tsfati, Yariv \& Weiman, Gabriel 2002. www.terrorism.com: Terrorism on the Internet. Studies in Conflict \& Terrorism, Vol. 25, No. 5, pp. 317-332.

Verkhovsky, Alexander 2006. Sova center report on hate speech in Russian Internet. http://www.sova-center.ru/en/, last accessed on 10 May 2010.

Wallace, Particia M. 1999. Psychology of the Internet. Cambridge: Cambridge University Press. 